\title{
Molecular Detection of Strongyloides ratti in Faecal Samples from Wild Rats in Serdang, Malaysia
}

\author{
Khalid Jameel Kadhim Al-Zihiry ${ }^{1,2}$, Mahmuda Aliyu ${ }^{1,3}$, Salman Sahab Atshan ${ }^{4}$, \\ Zasmy Unyah ${ }^{1}$, Zaid Osama Ibraheem ${ }^{5}$, Roslaini Abdul Majid ${ }^{1}$, Rukman Awang \\ Hamat ${ }^{1}$ and Wan Omar Abdullah ${ }^{1}$ \\ ${ }^{1}$ Medical Parasitology and Entomology Unit, Department of Medical Microbiology and Parasitology, Faculty of Medicine and \\ Health Sciences, Universiti Putra Malaysia, 47300 Serdang, Selangor, Malaysia, ${ }^{2}$ Department of Microbiology, College of \\ Medicine, Thi-Qar University, Iraq, ${ }^{3}$ Department of Parasitology and Entomology, Faculty of Veterinary Medicine, Usmanu, \\ Danfodiyo University, Sokoto, Nigeria, ${ }^{4}$ College of Nursing, Basrah University, Basrah, Iraq, ${ }^{5}$ Department of Pharmacology and \\ Toxicology, School of Medicine and Health Science, Universiti Putra Malaysia, 47300 Serdang, Selangor, Malaysia
}

*For correspondence: Email: kjkadhim@yahoo.com; Tel: +601129077590

\begin{abstract}
Purpose: To detect Strongyloides ratti in faecal samples using conventional methods and to confirm the identification using a sensitive and specific method, namely, polymerase chain reaction (PCR).

Methods: A PCR method targeting the small subunit of the rRNA gene was performed in this study for the detection of DNA from Strongyloides ratti (an animal model of S. stercoralis) in faecal samples of wild Brown rats, Rattus norvegicus.

Results: Strongyloides ratti was detected in $34.2 \%$ of collected rats by different conventional techniques and confirmed by PCR. The essay presented $100 \%$ sensitivity with Strongyloides universal primer.

Conclusion: The findings of this study suggest that the application of PCR with universal primer is a very sensitive methodology to detect $S$. ratti in faecal material of wild rats infected even with very low parasite burden.
\end{abstract}

Keywords: Faecal, Parasite, Strongyloides stercoralis, Strongyloides ratti, Brown rat, DNA, Universal primer

\begin{abstract}
Tropical Journal of Pharmaceutical Research is indexed by Science Citation Index (SciSearch), Scopus, International Pharmaceutical Abstract, Chemical Abstracts, Embase, Index Copernicus, EBSCO, African Index Medicus, JournalSeek, Journal Citation Reports/Science Edition, Directory of Open Access Journals (DOAJ), African Journal Online, Bioline International, Open-J-Gate and Pharmacy Abstracts
\end{abstract}

\section{INTRODUCTION}

Human parasite $S$. stercoralis, which was discovered for the first time in 1876 by Louis Normand, can cause a potentially fatal disease for immunosuppressed individuals or for those who are undergoing corticosteroid treatment. Approximately 30 million people are infected in 70 countries $[1,2]$. However, strongyloidiasis is a neglected parasitic disease the prevalence of which might be underestimated in many countries.
Eosinophilia could be an indication of $S$. stercoralis infection. However, it is usually mild $(5-15 \%)$ and nonspecific [2].Stool examination is still considered the primary technique for the detection of $S$. stercoralis infection. This routine method remains insensitive and dependent on the skill and training of the laboratory staff [3].

Highly efficient agar plate culture (APC) method can detect more than $90 \%$ of positive cases of strongyloidiasis, even when only a few worms 
are present. To assist in the primary identification using APC, some researchers suggested the analysis and comparison of the larval furrows left by Strongyloides and very close hookworms' species on the agar plate surface [4]. The mobility pattern of these larvae on the surface of agar can be exploited and used to confirm the diagnosis [5].

The disadvantage of this method is that, it is time consuming due to the minimal number and irregular output of the eggs and larvae in the stool, especially in cases of chronic infections. Moreover, fresh stool samples that have not been refrigerated are recommended for cultures as this method mainly dependent on the movement of live larvae over an agar plate surface [6,7]. To overcome the limitations of using the classical method utilized in the diagnosis of strongyloidiasis, various sensitive and specific molecular methods such as conventional Polymerase Chain Reaction (PCR)based technique have been developed. PCR has been associated with higher sensitivity than classical parasitological methods during infections with lower intensity $[3,8]$.

The rat-invading nematode Strongyloides ratti which is naturally occurring in wild rodents is an ideal organism to work with in the laboratory and is widely used as an experimental infection model to study strongyloidiasis [9]. Full length $S$. stercoralis small subunit rRNA (ssrRNA) gene sequence shows $90 \%$ identity with that of rat nematode, $S$. ratti and both sequences show similar identities to the Caenorhabditis elegans ssrRNA gene over full-length sequence (68\% and $70 \%$ identity with $S$. ratti and S. stercoralis, respectively) $[10,11]$.

In the present study, we aimed to provide a universal detection tool that can also be used in the S. stercoralis infection in clinical setting.

\section{EXPERIMENTAL}

\section{Rat collection}

Seventy wild Brown (Norway) rats, Rattus norvegicus were caught and examined. They were trapped in the period between January and March, 2013 from resident, shops, and restaurants areas of some places in Seri Serdang, Balakong, and South City. All the captured rats were maintained at the Animal Research Unit, Faculty of Medicine and Health Sciences, Universiti Putra Malaysia (UPM).

\section{Stool examination}

Stool samples were collected from trapped rats and direct faecal smear slides were prepared and examined under a light microscope to detect helminth eggs and rhabditiform larvae. Some slides were stained with Lugol's iodine stain to observe the internal structures of the detected stage. Detected stages were analysed using an Image Analysis Software (Nikon Corporation, Japan).

\section{Recovery of adult worms from small intestine}

Infected rats were killed with high doses of diethyl ether. The small intestines were removed, slit longitudinally and their contents were removed. The luminal surface was washed and incubated in warm $\left(\sim 34^{\circ} \mathrm{C}\right)$ physiological saline for $2 \mathrm{~h}$ using Baermann technique. Adult worms were then recovered from the sediments of Baermann funnel. Collected adults were fixed in $70 \%$ ethanol, cleared and mounted on slides for species identification

\section{Agar plate culture}

Agar Plate Culture (APC) method was performed for all collected stool samples. Briefly, $2 \mathrm{~g}$ of each sample was placed in the center of plastic petri dish containing approximately $20 \mathrm{~mL}$ of nutrient agar. Dishes were sealed with parafilm tape to prevent larvae from crawling out of the plate and were incubated at $26-28{ }^{\circ} \mathrm{C}$ (Labwit incubator, Shanghai, China). Plates were monitored daily for up to 3 days by stereomicroscope for the presence of marks of motile larvae and further extended for negative cases. After the crawling tracks were noticed, larvae were isolated by washing the agar surface with $10 \mathrm{~mL}$ of phosphate-buffered saline (PBS), cleaned with PBS several times, fixed on slides using some drops of Lugol's iodine solution and examined under light microscope. Isolated larvae were diagnosed based on the morphological characteristics and measurements.

\section{Molecular identification}

\section{DNA extraction}

Genomic DNA from eggs and rhabditiform larvae of $S$. ratti in fresh faecal samples was extracted with QIAamp DNA stool mini kit (QIAGEN, Hilden, Germany) as described by the manufacturer. The concentration and purity of the extracted DNA was measured using NanoDrop ${ }^{2} \quad$ ND-1000spectrophotometer (ThermoFisher Scientific, USA). DNA samples 
were aliquoted and stored in $-30{ }^{\circ} \mathrm{C}$ freezer for further use.

\section{Detection of 28S rDNA gene}

The oligonucleotides primer pair, StroS (Forward 5'-TTAGAGTCGTGTTGCTTGGAA-3'and StroAS (Reverse 5'-GTGCAACTGGCTCTGTATGC-3') [12] was used in the current assay. Strongyloides ratti partial $28 \mathrm{~S}$ rDNA sequence was obtained from the GenBank (accession U39490), submitted to BLAST and searched against Homo sapiens, Rattus norvegicus, Nippostrongylus brasiliensis, $S$. venezuelensis and $S$. muris genome sequences.

Final PCR reaction mix contains $12 \mu \mathrm{L}$ of $1 \mathrm{x}$ GoTaq ${ }^{\circledR}$ Green Master Mix (Promega, USA), 1-2 $\mu \mathrm{L}$ of each primer pair (0.1-1.0 $\mu \mathrm{M}), 1-5 \mu \mathrm{L}$ DNA template, and Nuclease-Free water up to $25 \mu \mathrm{L}$. A blank tube was used as a negative control to indicate absence of environmental contamination. Thermal cycling (Biometra, Germany) include initial denaturation at $95{ }^{\circ} \mathrm{C}$ for $5 \mathrm{~min}$, follows by 35 cycles of $95{ }^{\circ} \mathrm{C}$ for $5 \mathrm{sec}$ (denaturation), $50{ }^{\circ} \mathrm{C}$ for $20 \mathrm{sec}$ (annealing for primer pair), $72{ }^{\circ} \mathrm{C}$ for $30 \mathrm{sec}$ (extension) and 72 ${ }^{\circ} \mathrm{C}$ for 5 min (final extension).

\section{Gel electrophoresis of PCR product}

PCR products were analyzed on agarose gel electrophoresis in $1 \%$ of $1 \mathrm{X}$ TBE buffer prestained with $1 \mathrm{X}$ GelRed at $80 \vee \mathrm{V}$ for $2 \mathrm{~h}$. Molecular markers (Vivantis, UK) were run as indicators of the size of PCR amplicon. Gels were visualized under UV light transilluminator and photographed.

\section{Gene sequencing and alignment}

PCR products from representative samples were purified using QIAquick PCR purification kit (QIAGEN, Hilden, Germany) as described by the manufacturer and sent for sequencing (FirstBase, Singapore) to confirm the identity of the gene sequence. The nucleotide sequence was then downloaded and aligned with those from the GenBank database to obtain the percentage of homology using BLAST (www.ncbi.nlm.nih.gov/BLAST).

\section{RESULTS}

\section{Morphological characterization of S. ratti}

Out of 70 rat samples collected from study sites, $24(34.2 \%)$ were found microscopically positive (Figure 1).
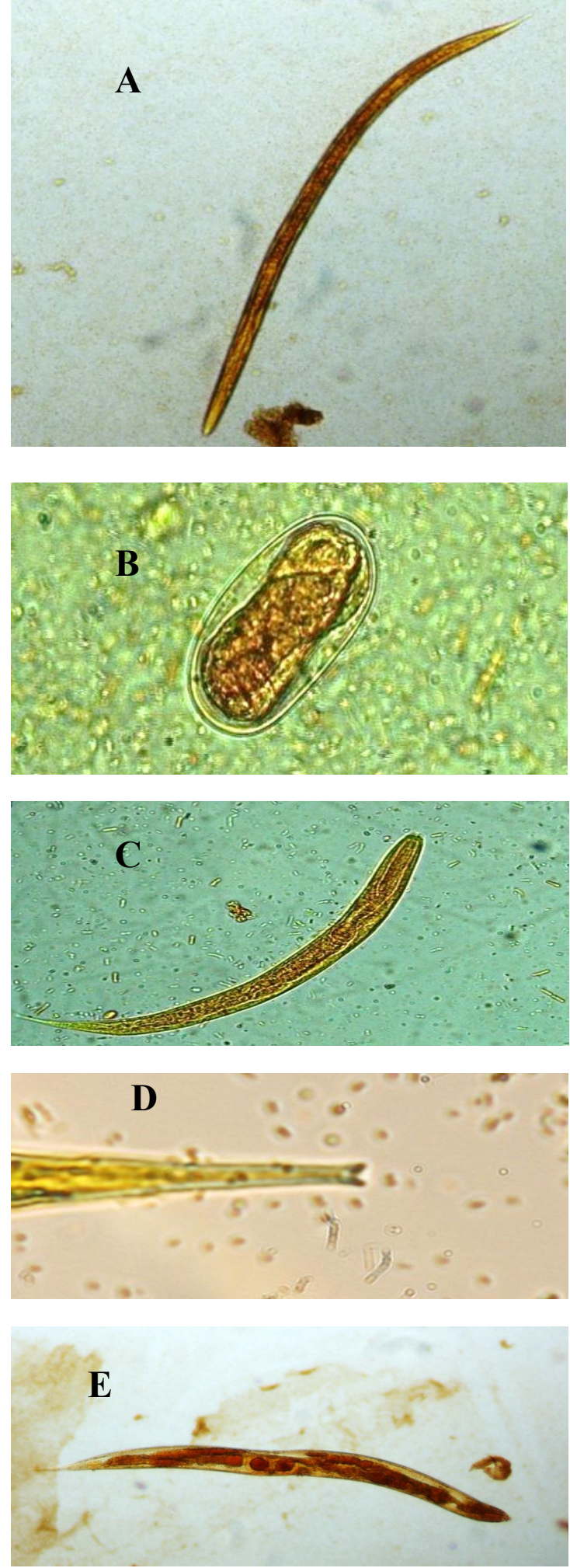

Figure 1: Strongyloides ratti from present study. A: Egg; B: Rhabditiform larva; C: Whole filariform larva; D: Notched tail of filariform larva; E: Free-living adult worms

Agar Plate Culture (APC) result confirmed the positive cases by monitoring the mobility pattern of nematode larvae on the surface of an agar 
plate and differentiate larval stages of Strongyloides from those closely related, hookworm species.

Parasitological examination of stool samples revealed the presence of all parasitic stages of nematode that were identified as $S$. ratti based on the following characteristic features.

\section{Eggs}

The eggs were identical in appearance, though slightly variable in size and ellipsoidal with extremely thin walls. The dimension of width was about half that of length. Eggs of parasitic female in early cleavage when deposited may or may not undergo development before leaving the host.

\section{Rhabditiform larvae}

Newly hatched larvae with bulbed esophagus of nearly one-third body length. The head and two cephalic lobes separated by transversely elongated, oval mouth. Buccal cavity (stoma) is short. Nerve ring at anterior end. Intestine patent. Visible genital primordium and the tail ending abruptly.

\section{Filariform larvae}

The larvae were slender, esophagus filariform with a length approximately $40 \%$ that of body length with no prominent bulb, tail notched, cuticle finely striated; lateral alae double. The head bearing two inconspicuous lateral cephalic lobes, mouth small, and pore like, buccal cavity shallow.

\section{Parasitic female}

Parthenogenetic females live embedded in mucosal epithelium of the gastrointestinal tract, slender in shape and body wall thin. Cuticle finely striated. The tail is short and abruptly tapered. The head with circumoral elevation, lips lacking. Mouth dorso-ventrally elongated with shallow buccal cavity. Esophagus is long and composed of two distinct portions, muscular portion, anterior to the nerve ring and posterior glandular portion. Reproductive system without seminal receptacle. The Vulva is about two-third body length from anterior end, a pair of prominent muscles surround a transverse opening. Vagina and oviduct are short. Ovaries long, with reflexed loops spiraling around the intestine or running parallel with intestine. Eggs in single row in uterus.
The direct smear method had the lowest sensitivity for the detection of $S$. ratti $(25.7 \%)$, identifying rhabditiform larvae and eggs only in 18 cases.

Agar plate culture increased the number of $S$. ratti positive samples detected by direct smear by $25 \%$, diagnosing an additional 6 cases that were not diagnosed by direct smears (Figure 2).

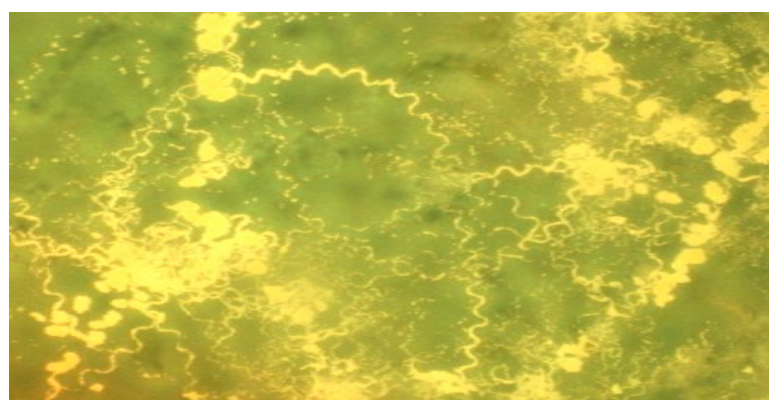

Figure 2: Agar plate culture of the stool samples from wild rat infected with Strongyloides ratti, arrows indicate the tracks of the infective larvae

\section{Molecular characteristics of S. ratti}

DNA from the isolated nematode morphologically identified as $S$. ratti by direct faecal smear and APC were successfully extracted. A 180 bp amplification band was obtained by PCR using DNA samples extracted from all these samples. No bands were noticed in the negative control sample indicating that there was no contamination in the reaction and the amplicon only resulted from the DNA amplification of the isolated nematode (Figure 3). PCR products that were sent for sequencing found to be $91 \%$ homologous of $S$. ratti $28 S$ rDNA nucleotide sequence (GenBank accession number U39490).

Polymerase Chain Reaction was a highly sensitive method for the detection of DNA of $S$. ratti, identifying $100 \%$ of the positive cases with APC technique. Diagnostic specificity was $100 \%$ for all samples that identified by the conventional diagnostic methods.

\section{DISCUSSION}

Soil-transmitted helminths have a significant impact on public health in affected countries [13]. Many parts of Southeast Asia are ideal ecological and socio-economical settings for $S$. stercoralis. Reported cases from some Asian countries showed prevalence rates above $20 \%$ for S. stercoralis $[14,15]$. Precise and reliable 


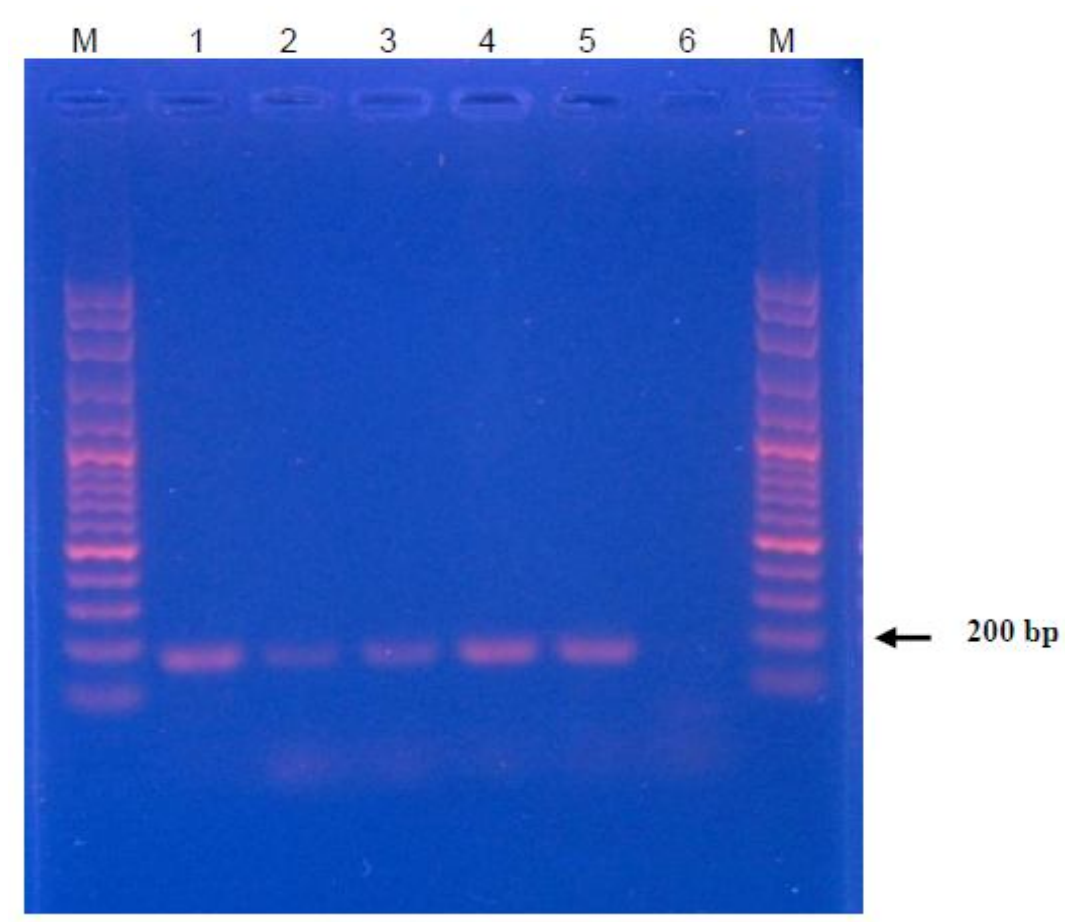

Figure 3: PCR amplification of $28 S$ rDNA gene using universal primer. Note: $M=100$ bp; Ladders: $1-5=P C R$ products from selected samples $(180 \mathrm{bp}) ; 6=$ negative control

diagnostic methods remain crucial for public health interventions as the prevalence of $S$. stercoralis still underestimated due to low sensitivity of routinely diagnostic techniques [2].

The time required, high costs are the main reasons that clinical laboratories do not prefer APC for the routine diagnosis of strongyloidiasis. Furthermore, the technician exposure to the infective filariform larvae is the main risk associated with this technique. This could be reduced if $A P C$ is carefully manipulated.

The efficiency and sensitivity of APC were confirmed in this study as the direct stool examination failed to detect 6 cases of $S$. ratti that were detected by APC and confirmed by PCR.

For time saving, all stool samples in the current study were subjected to a single stool examination by APC. Based on Zaha et al [16], single examination of stool specimen by APC would detect most of $S$. stercoralis infections, repeating an examination may not be necessary and usually does not increase the detection rate significantly from that of the first examination. However, it is highly recommended that APC method should be performed for at least four consecutive days and daily search for furrows of parasitic stage of $S$. stercoralis on agar to increase the sensitivity of the technique.
The difference can be attributed to the high $S$. ratti burden in this study in comparison with most studies which documented low burden of $S$. stercoralis in human stool. The majority of positively recorded cases of $S$. ratti had high output of eggs and rhabditiform larvae. These stages in most of our cases can easily be seen in the direct stool smear preparation except for those which were negative using this method. Negative cases with direct smear were also successfully identified by performing a single examination with the APC which may support the hypothesis that APC is less likely to be affected by the fluctuation of eggs and larval output noticed in the conventional direct smear preparations as mention by Uparanukraw et al [17].

Our molecular assay was designed to target the 28S rRNA gene sequence of Strongyloides species, exists in various copies. So, the probability of detection of this gene should be increased compared to that of single copy genes. Targeting multi-copy genes has already extensively been used for other pathogens [12].

The assay allows the simultaneous detection of S. ratti, S. stercoralis, S. fuelleborni, S. robustus, $S$. calloscinreus and $S$. procyonis. Among them, only $S$. ratti is known to cause infection in rat, which increases the specificity of this assay for definitive identification of $S$. ratti. 
Strongyloides ratti was first recorded in Malaysia by Hall [18] from unidentified house rats. Furthermore, Dunn et al [19] described helminth parasites of rats including $S$. ratti from Pulau Tiomon and Pulau Tikus islands. Leong et al [20] and Inder et al [21] completed the description of $S$. ratti and ten (10) other nematodes from house rat $R$. rattus in Kuala Lumpur and Ulu Endau, Johor, respectively. Furthermore, in the study of Sinniah [22], S. ratti and Angiostrongylus cantonensis were found the most prevalent nematode infections in eight (8) rodent species in peninsular Malaysia. Strongyloides ratti was identified from all the above studies based on morphological characteristics and no molecular confirmation was introduced.

Strongyloides ratti and $S$. venezuelensis are similar; their rhabditiform or filariform larvae resemble each other morphologically and very difficult to distinguish between species based on morphology. However, they are significantly separated genetically (mostly through apomorphic changes in the $S$. venezuelensis ssrDNA gene sequence) despite inhabiting the same hosts [23]. This point could be positively exploited to molecularly differentiate between the two common rat's nematodes using current assay.

Molecular methods established for identification of Strongyloides spp. could be useful for the early diagnosis of strongyloidiasis in asymptomatic patients that will undergo immunosuppressive therapy [24-26]. However, optimization of DNA extraction and PCR assays for the detection of intestinal nematodes in stools are challenging due to the presence of complex and resistant cuticle of nematodes and bacterial proteases, nucleases, cell debris, and bile acids that are relatively common in stools, which may inhibit DNA amplification and negatively influence the PCR results $[27,28]$.

\section{CONCLUSION}

This is the first molecular identification of the nematode $S$. ratti in Malaysian rats. The present study provides evidence based on the combination of conventional and molecular tools for a definitive diagnosis of strongyloidiasis. It depends on the microscopic demonstration of parasites, increasing the sensitivity of the detection that would require the use of different parasitological methods, including PCR. There is yet no reported case of infection in rats with Strongyloides species in Malaysia other than $S$. ratti. The present study shows that 28S rDNA, as a genetic marker, exhibits a high level of specificity to $S$. ratti. The technique potentially amplifies DNA of other Strongyloides species, such as S. stercoralis, S. fuelleborni, S. robustus, $S$. calloscinreus and $S$. procyonis, but does not amplify DNA from a range of other common rat nematodes in Malaysia.

\section{ACKNOWLEDGEMENT}

This work was supported by grants from the Ministry of Higher Education Malaysia (no. 0401-11-1067FR), Ministry of Science, Technology and Innovation Malaysia (no. 02-01-04-SF1655) and Universiti Putra Malaysia (no. 04-02-122097RU).

\section{REFERENCES}

1. Janwan $P$, Intapan PM, Thanchomnang $T$, Lulitanond $V$, Anamnart $W$, Maleewong $W$. Rapid detection of Opisthorchis viverrini and Strongyloides stercoralis in human fecal samples using a duplex real-time PCR and melting curve analysis. Parasitol Res 2011; 109:1593-1601.

2. Siddiqui AA, Berk SL. Diagnosis of Strongyloides stercoralis infection. Clin Infect Dis 2001; 33(7): 1040-1047.

3. Marra NM, Chiuso-Minicucci F, Machado GC, Zorzella-Pezavento SF, França TG, Ishikawa LL, Amarante AF, Sartori A, Amarante MR. Faecal examination and PCR to detect Strongyloides venezuelensis in experimentally infected Lewis rats. MemInst Oswaldo Cruz (2010); 105:57-61

4. Ines Ede J, Souza JN, Santos RC, Souza ES, Santos FL, Silva MLS, Silva MP, Teixeira M CA, Soares NM. Efficacy of parasitological methods for the diagnosis of Strongyloides stercoralis and hookworm in faecal specimens. Acta Trop 2011; 120: 206-210.

5. Jongwutiwes $S$, Charoenkorn $M$, Sitthichareonchai $P$, Akaraborvorn P, Putaporntip C. Increased sensitivity of routine laboratory detection of Strongyloides stercoralis and hookworm by agar-plate culture. Trans Roy Soc Trop MedHyg 1999; 93: 398-400.

6. Knopp S, Mgeni AF, Khamis IS, Steinmann, P, Stothard $J R$, Rollinson D, Marti $H$, Utzinger J. Diagnosis of soil-transmitted helminths in the era of preventive chemotherapy: effect of multiple stool sampling and use of different diagnostic techniques. PLosNegITro. Dis2008; 2, e331.

7. Requena-Mendez A, Chiodini P, Bisoffi Z, Buonfrate D, Gotuzzo E,Munoz J. The laboratory diagnosis and follow up of strongyloidiasis: a systematic review. PlosNegl Trop Dis; 2013; 7: e2002.

8. Wongratanacheewin S, Pumidonming $W$, Sermswan RW, Maleewong W. Development of a PCR-based method for the detection of Opisthorchis viverriniin experimentally infected hamsters. Parasitology 2001; 122: 175-180.

Trop J Pharm Res, July 2015; 14(7): 1172 
9. Viney ME. Exploiting the life cycle of Strongyloides ratti. Parasitol Today 1999; 15: 231-235.

10. Dorris M, Blaxter M. The small subunit ribosomal RNA sequence of Strongyloides stercoralis. Int J Parasitol 2000; 30(8): 939-941.

11. Mitreva M, McCarter JP, Martin J, Dante M, Wylie $T$, Chiapelli B, Pape D, Clifton SW, Nutman TB, Waterston RH. Comparative Genomics of Gene Expression in the Parasitic and Free-Living Nematodes Strongyloides stercoralis and Caenorhabditis elegans. Genome Res 2004; 14: 209220.

12. Kramme S, Nissen N, Soblik H, Erttmann K, Tannich E, Fleischer B, Panning M, Brattig N. Novel real-time PCR for the universal detection of Strongyloides species. J MedMicrobiol 2011; 60 (4): 454-458.

13. Bethony J, Brooker S, Albonico M, Geiger SM, Loukas A, Diemert D, Hotez PJ. Soil-transmitted helminth infections: Ascariasis, trichuriasis, and hookworm. Lancet 2006; 367: 1521-1532.

14. Chhakda $T$, Muth $S$, Socheat $D$, Odermatt $P$. Intestinal parasites in school aged children in villages bordering Tonle Sap Lake, Cambodia. Southeast Asian J Trop Med Public Health 2006; 37: 859-864.

15. Khieu V, Srey S, Schär F, Muth $S$, Marti H. Odermatt $P$. Strongyloides stercoralis is a cause of abdominal pain, diarrhea and urticaria in rural Cambodia. BMC Res Notes 2013; 6(1): 200.

16. Zaha $O$, Hirata $T$, Kinjo $F$, Saito A. Strongyloidiasis Progression, diagnosis and treatment. Intern Med 2000; 39:695-700.

17. Uparanukraw P, Phongsri S, Morakote N. Fluctuations of larval excretion in Strongyloides stercoralis infection. Am J Trop Med Hyg1999; 60, 967-973.

18. Hall MC. Nematode parasites of mammals of the orders Rodentia, Lagomorpha and Hyracoidea. Proc U.S. Natural Museum, 1916; 50: 1-258.

19. Dunn FL, Lim B, Yap LP. Endoparasite patterns in mammals of the Malayan Rain Forest. JEcol 1968; 49: $1180-1184$.
20. Leong TS, Lim BL, Yap Loy Fong, Krishnasamy M. Parasite fauna of the house rat Rattusrattus diardiiin Kuala Lumpur and nearby villages. Southeast Asian J Trop Med Public Health 1979; 10(1):122-126.

21. Inder S, Krishnasamy $M$, and Ho Tse Ming. Collection of small vertebrates and their endoparasites from Ulu Endau, johor Malaysia. Malaysian Heritage and Scientific Expedition of Endau Rompin. Malaysian. Nature J 1987; 41: 349-356

22. Sinniah B, Manmohan S, Khairul A. Preliminary survey of Capillaria hepatica (Bancroft, 1893) in Malaysia. J Helminthol 1979; 53: 147-152.

23. Dorris M, Viney M E, Blaxter ML. Molecular phylogenetic analysis of the genus Strongyloides and related nematodes. Int J Parasitol 2002; 32: 1507-1517.

24. Verweij J, Canales M, Polman K, Ziem J, Brienen E, Polderman A, Van Lieshout L. Molecular diagnosis of Strongyloides stercoralis in faecal samples using real-time PCR. Trans Roy Soc Trop MedHyg 2009; 103: 342-346.

25. Gordon C, Gray D, Gobert G, cManus D. DNA amplification approaches for the diagnosis of key parasitic helminth infections of humans. Mol Cell Probes 2011; 25: 143-152.

26. Schar F, Odermatta $P$, Khieua V, Panninge M, Duongc $S$, Muthc S, Marti H. Kramme S. Evaluation of realtime PCR for Strongyloides stercoralis and hookworm as diagnostic tool in asymptomatic school children in Cambodia. Acta Trop 2013; 126: 89-92

27. Al-Soud Waleed W, Radstrom P. Effects of amplification facilitators on diagnostic PCR in the presence of blood, feces, and meat. J Clin Microbiol 2000; 38:4463-4470.

28. Repetto SA, Alba Sotoa CD, Cazorlaa SI, Tayeldina ML, Cuelloa S, Lasalab MB, Tekielc VS, Gonzlez Cappaa $S M$. An improved DNA isolation technique for PCR detection of Strongyloides stercoralis in stool samples. Acta Trop 2013; 126: 110-114. 